\title{
Correction to: Ustekinumab Safety in Psoriasis, Psoriatic Arthritis, and Crohn's Disease: An Integrated Analysis of Phase II/III Clinical Development Programs
}

\author{
Subrata Ghosh ${ }^{1}$ - Lianne S. Gensler ${ }^{2} \cdot$ Zijiang Yang $^{3} \cdot$ Chris Gasink $^{4}$. Soumya D. Chakravarty ${ }^{4,5} \cdot$ Kamyar Farahi $^{4}$. \\ Paraneedharan Ramachandran ${ }^{3}$. Elyssa Ott ${ }^{4}$ Bruce E. Strober ${ }^{6,7}$
}

Published online: 22 April 2019

(c) The Author(s) 2019

\section{Correction to: Drug Safety https://doi.org/10.1007/s40264-019-00797-3}

In the original publication of this article, the following correction should be noted in Table 5 .

The 95\% CI for serious infections in the Ustekinumab -MTX group under PsA should read 0.8-3.5 and not 0.8-3.5.5.
Open Access This article is distributed under the terms of the Creative Commons Attribution-NonCommercial 4.0 International License (http://creativecommons.org/licenses/by-nc/4.0/), which permits any noncommercial use, distribution, and reproduction in any medium, provided you give appropriate credit to the original author(s) and the source, provide a link to the Creative Commons license, and indicate if changes were made.
The original article can be found online at https://doi.org/10.1007/ s40264-019-00797-3.

Subrata Ghosh

s.ghosh@bham.ac.uk

Lianne S. Gensler

Lianne.Gensler@ucsf.edu

Zijiang Yang

zyang43@its.jnj.com

Chris Gasink

CGasink@its.jnj.com

Soumya D. Chakravarty

schakr66@its.jnj.com

Kamyar Farahi

KFarahi@its.jnj.com

Paraneedharan Ramachandran pramach4@its.jnj.com

Elyssa Ott

EOtt1@its.jnj.com

Bruce E. Strober strober@uchc.edu
Institute of Translational Medicine and NIHR Birmingham Biomedical Research Centre, University of Birmingham, Office 04, Ground Floor, ITM, North Block, Heritage Building, Mindelson Way, Edgbaston, Birmingham B15 2TH, UK

2 Axial Spondyloarthritis Clinic, University of California San Francisco, 400 Parnassus Ave., Floor B1, San Francisco, CA 94143, USA

3 Janssen Research \& Development, LLC, 1400 McKean Road, Spring House, PA 19477, USA

4 Janssen Scientific Affairs, LLC, 800 Ridgeview Drive, Horsham, PA 19044, USA

5 Drexel University College of Medicine, 219 N. Broad Street, Floor 9, Philadelphia, PA 19107, USA

6 Department of Dermatology, University of Connecticut Health Center, 21 South Road, 2nd Floor, Farmington, CT 06030, USA

7 Probity Medical Research, 135 Union Street E, Waterloo, ON N2J 1C4, Canada 